\title{
The Origins of Certainty
}

\author{
STEPHEN H. DANIEL
}

Hugh $M$. Davidson: The origins of Certainty: Means and Meanings in Pascal's Pensees. TChicago: University of Chicago press, 1979.) pp. xi, 158. Cloth, $\$ 13.50$.

Because Pascal's Pensees is a labyrinth of puzzling and provocative observations often difficult to place within the mainstream of seventeenth century philosophy, it has often been relegated to a secondary status by historians concerned with the period. Recently the work's abrupt and discontinuous character as a loose collection of more or less developed thoughts--a feature which has frustrated many minds more accustomed to the flow of the writing of a Descartes or a Hobbes--has attracted the attention of writers such as Follcault and deconstructionist historians of literary criticism such as Paul deMan and Jacques Derrida. More sympathetic to the characteristics of dialectic tension in thinkers like Pascal and Nietzsche, deMan, Foucault, Derrida, and others infuse their analyses of philosophic works with a strong concentration on how rhetorical and semiotic features contribute to the understanding of the works as comunicative contexts out of which meaning emerges. Pascal and Nietzsche are favorites for such an approach, in that the forms of the pensee or the aphorism invite repeated return and reinterpretation due to their terse and of ten paradoxical tenor; such forms also emphasize the discontinuities and discuptions of thought implicit not only in the recurrent generation of new meanings in new readings of the texts but also in the author's presentation of the movenent of thought as a sometimes halting, sometines cryptic and unsettling process. 
As his subtitle indicates, Hugh Davidson approaches the question of certainty in the Pensees on two different methodological levels: one in which the more traditional philosophic theme of the means to attain certainty are discussed, and the other in which the complexes of Pascal's words, terms, and meanings surrounding the issue of certainty are exanined in order to "glimpse through the underlying mental states and tensions that give rise to the text." This second methodological interest serves as the point of unity between Davidson's work and that of others also interested in literary criticism.

Davidson's intention is to inquire into the function and meaning of the notion of proof in the Pensees in an attempt to show how pascal uses four types of proof (geometric, syllogistic, dialectic, and pragmatic) to provide the means to a faith in God which cannot be doubted. According to Davidson, such a treatment of proof--encompassing as it does a process of growth in conviction for man seen as a practicalreligious-reasoning unity and not simply limited to the demonstrations of reason alone--serves to explain Pascal's views on the means by which (1) reason opens the mind up to the more humanly integrating types of proofs, (2) custom or habit strengthens one's attachment to these proofs, and (3) inspiration brings true conviction not only in the existence of God but more importantly in the unified relationship of God, man, and Nature as a context in which rational certainty and faith gain meaning. Within such a description, Davidson is able to point out how Pascal's famous wager is nether a beginning of a convincing proof in God nor an end reluctantly accepted because of the inability to provide a rational proof. Instead, the wager is seen to be a part of a complete convincing process--a process which begins with the nonexclusionary activity of reason and which is made stable through practice and custom and provided with the hope-filled immediacy sought after by men as passional, spiritual, as well as rational beings.

Pascal is a difficult writer to try to describe in ways other than his own, and Davidson avoids the pitfalis of a systematic or discursive treatment by adopting the sometimes sporadic way of writing found in his author. We bounce with Davidson, as we do with Pascal, from one pensee to another, forced to rely oll our own sense of direction to get us over the discontinuities in Davidson's as well as Pascal's prose. certainly this is not a book for those unwilling to attenpt to penetrate the mental states and 
tensions that give rise to Davidson's text or those unable to grapple with Pascal's own terseness (the numerous quotations from Pascal are in French without translations). As with any attempt to make Pascal more accessible, Davidson has to try to present Pascal in terms of a clarifying continuity where Pascal pulls us constantly back to the insistence of cognitive and linguistic disruption. For his part, Davidson keeps us within the pascalian mind and way of writing and thus requires from the beginning a reader sympathetic to and willing to struggle with pascal.

Spring Hill College 